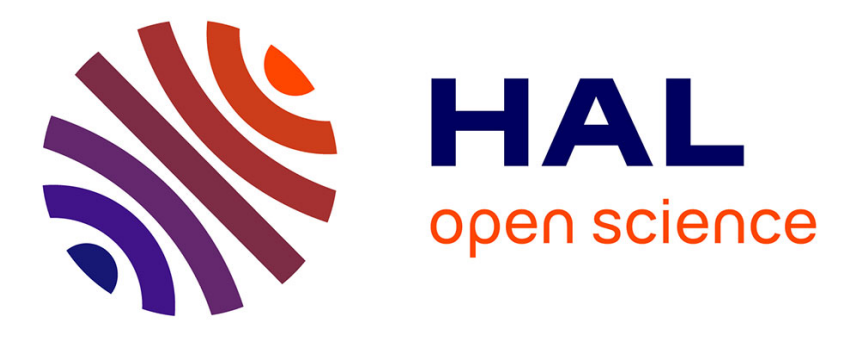

\title{
Fast beam-based analysis of monostatic scattering
}

\author{
Christine Letrou, Igor Gershenzon, Mossaab Hariz, Amir Boag
}

\section{To cite this version:}

Christine Letrou, Igor Gershenzon, Mossaab Hariz, Amir Boag. Fast beam-based analysis of monostatic scattering. ICEAA 2017: 19th International Conference on Electromagnetics in Advanced Applications, Sep 2017, Verona, Italy. pp.810 - 811, 10.1109/ICEAA.2017.8065373 . hal-01686710

\section{HAL Id: hal-01686710 https://hal.science/hal-01686710}

Submitted on 17 Jan 2018

HAL is a multi-disciplinary open access archive for the deposit and dissemination of scientific research documents, whether they are published or not. The documents may come from teaching and research institutions in France or abroad, or from public or private research centers.
L'archive ouverte pluridisciplinaire HAL, est destinée au dépôt et à la diffusion de documents scientifiques de niveau recherche, publiés ou non, émanant des établissements d'enseignement et de recherche français ou étrangers, des laboratoires publics ou privés. 


\title{
Fast Beam-based Analysis of Monostatic Scattering
}

\author{
C. Letrou $^{1}$ \\ I. Gershenzon ${ }^{2}$ \\ M. Hariz ${ }^{3}$ \\ A. Boag $^{4}$
}

\begin{abstract}
A fast Gaussian beam shooting (GBS) algorithm for monostatic scattering over a range of angles is developed. The algorithm exploits the beam localization in the near- and farfields with only few beams contributing to the back scattered field. The results are compared to those of iterative physical optics.
\end{abstract}

\section{INTRODUCTION}

Three dimensional analysis of monostatic scattering in urban-like environments, comprising numerous large smooth surfaces, requires computationally intensive simulations. Gaussian beam shooting (GBS) algorithms [1] are well suited for such simulations involving multiple reflections and near field interactions. Our goal in this paper is to develop a beam-based computational technique with the complexity comparable to that of Geometrical Optics (GO). The accuracy of the obtained results will be established through comparisons with Iterative Physical Optics (IPO) results [2, 3].

\section{PROBLEM FORMULATION}

We consider a scattering problem where incident radiation undergoes several bounces before being returned back to the source, with the maximum number of bounces $B$ being finite and greater than 2 . Let $P$ denote the maximum length of the GO rays between the first and last reflection points. We define $N=(k R)^{2}$ as a large parameter to estimate the computational complexity of computing the far-field monostatic scattering pattern over a range of elevation and azimuth angles. The number of directions (elevation/azimuth angles) required to describe the scattering pattern over a finite angular sector is of $O(N)$. The number of rays to be launched to represent the incident plane wave is also of $O(N)$. Assuming efficient ray tracing, i.e., $O(1)$ operations per GO ray, simple GO propagation of $O(N)$ rays through multiple reflections costs $O(B N)$ and the total computation complexity of GO is equal to $O\left(B N^{2}\right)$ in order to compute the field in the output plane. The final FFT needed to obtain the far field in the direction of back radiation does not modify this asymptotic complexity.

\section{GBS ALGORITHM}

In the proposed GBS algorithm, the incident field on or near the first reflecting surface is expanded into a superposition of frame windows, each of which radiates in the form of a beam propagating from the first to the last surface. The frame window parameters are chosen so that the beams remain collimated at least until they reach the last reflecting surface, i.e., $b>P$ where $b$ is the beam collimation distance, $L^{2} / \lambda$, with $L$ being the frame window width parameter. The Gaussian beam width $L$ should be small compared to the size of the surfaces, i.e. $L<<$ $R$. Gaussian beam bouncing involves the same complexity as ray bouncing, hence direct summation of $O(N)$ beams for $O(N)$ values of the far field angles $\gamma$, and $B$ bounces, yields a computational complexity equal to $O\left(B N^{2}\right)$. It should be noted that the far field of a Gaussian beam is known analytically, hence the direct summation of beams yields the monostatic pattern in a straightforward manner:

$$
U(\gamma)=\Sigma_{\mu} a_{\mu}(\gamma) B_{\mu}(\gamma)
$$

where $\boldsymbol{\mu}=\left(m_{1}, m_{2}, n_{1}, n_{2}\right)$ is a composite beam index including two spatial and two spectral indices $\boldsymbol{m}=$ $\left(m_{1}, m_{2}\right)$ and $\boldsymbol{n}=\left(n_{1}, n_{2}\right)$, respectively. Also in (1), $a_{\mu}(\gamma)$ represents the beam excitation amplitude after the scattering process, and $B_{\mu}(\gamma)$ - the outgoing farfield beam field in direction $\gamma$, resulting from the bouncing of the beam initially radiated by the $w_{\mu}$ source frame window.

Only few of the frame windows representing the incident field are expected to contribute to the monostatic back-scattered field, due to their spectral localization. Hence most of the coefficients, $a_{\mu}(\gamma)$, should be negligible. Scatterers will be characterized according to the sparseness and localization of nonzero coefficients in the matrix of the $a_{\mu}\left(\gamma_{\tau}\right)$ coefficients, with $\tau=(p, q)$ being the composite index for the grid of far field directions $\left(\theta_{p}, \varphi_{q}\right)$. Thanks to the sparseness of this matrix, the proposed GBS algorithm is expected to be more efficient than the IPO [3] while maintaining comparable accuracy.

\footnotetext{
${ }^{1}$ Télécom SudParis, Lab. SAMOVAR (CNRS UMR 5157), Evry, France;

e-mail: christine.letrou@,telecom-sudparis.eu

${ }^{2}$ School of Electrical Engineering, Tel Aviv University, Tel Aviv 69978, Israel;

e-mail: igorgers@post.tau.ac.il

${ }^{3}$ Télécom SudParis, Lab. SAMOVAR (CNRS UMR 5157), Evry, France;

e-mail: mossaab.hariz@telecom-sudparis.eu

${ }^{4}$ School of Electrical Engineering, Tel Aviv University, Tel Aviv 69978, Israel; e-mail: boag@eng.tau.ac.il
} 


\section{References}

[1] D. Lugara, C. Letrou, A. Shlivinski, E. Heyman, and A. Boag, "Frame-based Gaussian beam summation method: Theory and application," Radio Science, vol. 38, no. 2, Apr. 2003.

[2] R. J. Burkholder, C. Tokgöz, C. J. Reddy, and W. O. Coburn, "Iterative physical optics for radar scattering predictions," Appl. Comput. Electromagn. Soc. J., vol. 24, no. 2, pp. 241-258, 2009.

[3] I. Gershenzon, A. Boag, and Y. Brick, "Fast iterative physical optics with shadowing," 2016 IEEE International Symposium on Antennas and Propagation, pp. 1363-1364. 